\title{
Interaction of colon cancer cells with glycoconjugates triggers complex changes in gene expression, glucose transporters and cell invasion
}

\author{
ROMANA KŘIVOHLAVÁ, VALIKA GROBÁROVÁ, EVA NEUHÖFEROVÁ, \\ ANNA FIŠEROVÁ and VERONIKA BENSON
}

Laboratory of Molecular Biology and Immunology, Department of Immunology, Institute of Microbiology,

Czech Academy of Sciences, 14220 Prague 4, Czech Republic

Received September 21, 2017; Accepted December 15, 2017

DOI: $10.3892 / \mathrm{mmr} .2018 .8490$

\begin{abstract}
Glycan metabolism balance is critical for cell prosperity, and macromolecule glycosylation is essential for cell communication, signaling and survival. Thus, glycotherapy may be a potential cancer treatment. The aim of the present study was to determine whether combined synthetic glycoconjugates (GCs) induce changes in gene expression that alter the survival of colon cancer cells. The current study evaluated the effect of the GCs $N$-acetyl-D-glucosamine modified polyamidoamine dendrimer and calix[4]arene scaffold on cancer cell proliferation, apoptosis, invasion and sensitivity to immune cell-mediated killing. Using reverse transcription-quantitative polymerase chain reaction, the expression of genes involved in the aforementioned processes was measured. It was determined that GCs reduce the expression of the glucosaminyltransferases Mgat 3 and Mgat 5 responsible for surface glycosylation and employed components of the Wnt signaling pathway $W n t 2 B$ and $W n t 9 B$. In addition, the calix[4]arene-based GC reduced cell colony formation; this was accompanied by the downregulation of the metalloproteinase $\mathrm{Mmp} 3$. By contrast, the dendrimer-based GC affected the expression of the glucose transporter components Sgltl and Egfrl. Therefore, to the best of our knowledge, the present study is the first to reveal that $\mathrm{N}$-acetyl-D-glucosamine-dendrimer/calix[4]arene GCs alter
\end{abstract}

Correspondence to: Dr Veronika Benson, Laboratory of Molecular Biology and Immunology, Department of Immunology, Institute of Microbiology, Czech Academy of Sciences, Vídeňská 1083, 14220 Prague 4, Czech Republic

E-mail: benson@biomed.cas.cz

Abbreviations: GC, glycoconjugate; GlcNAc, $N$-acetylglucosamine; GN4C, $N$-acetyl-D-glucosamine-coated calix[4]arene; GN8P, $\mathrm{N}$-acetyl-D-glucosamine-coated polyamidoamine dendrimer; PAMAM, polyamidoamine; PBMC, peripheral blood mononuclear cells; RTCA, Real-Time Cell Analyzer

Key words: calix[4]arene, polyamidoamine dendrimer, glycosylation, $\mathrm{N}$-acetyl-glucosaminyl-transferase, WNT, colon cancer cell
mRNA expression in a comprehensive way, resulting in the reduced malignant phenotype of the colon cancer cell line HT-29.

\section{Introduction}

Cell surface glycans are molecules that regulate interactions among neighboring cells or contact between cells and the extracellular matrix during cell adhesion, recognition and communication (1). An aberrant glycosylation pattern promotes the development and progression of certain pathologies, including cancer (1). Glycan alterations may result in tumor development and progression, as well as tumor-cell dissociation and invasion, which subsequently promote metastasis and tumor-associated neoangiogenesis (2). Importantly, aberrant glycosylation of the tumor cell surface results in the impairment of its recognition by cells of the immune system, including natural killer (NK) cells $(2,3)$.

Alterations inglycosylation primarily arise from changesin the expression of $\mathrm{N}$-acetyl-D-glucosamine (GlcNAc) transferases in the Golgi system (4). The family of $\beta-1,4-$ mannosyl-glycoprotein $4-\beta-N$-acetyl glucosaminyltransferases consists of several members, including Mgat3 and Mgat5, which are involved in linking terminal residues to glycans on the cell surface. The competition between Mgat 3 and Mgat5 results in the branching or bisecting of surface glycans and this final pattern influences intercellular recognition (5). Mgat5 is responsible for adding $\beta 1-6$ GlcNAc residues and forming branched structures, which are particularly abundant in cancer tissues with high metastatic potential (4). Mgat3 facilitates the addition of $\beta 1-4$ GlcNAc residues and constructs a bisecting structure that inhibits further addition of GlcNAc by other glucosaminyltransferases, including Mgat5 (6). Mgat 3 and Mgat5 enzymes tend to be overexpressed in tumor cells $(2,7)$. Song et al (8) reported that bisecting GlcNAc on N-glycans inhibits the signaling of growth factors and attenuates the progression of mammary tumors. Therefore, the resulting effect of Mgat3/Mgat 5 activity is likely to be tumor specific. The expression of Mgat5 is regulated via the NM23 regulator, which is encoded by Nmel gene (9) and the expression of glucosaminyltransferases, including Mgat 3 and Mgat5, is associated with their surface glycosylation activity (10). 
In vitro, cell glycosylation may be studied using synthetic glycoconjugates (GCs) that modulate cell surface glycosylation. GCs are able to interfere with cancer cell processes and the cancer microenvironment; therefore they may be able to modulate the malignant phenotype of cancer cells (11).

The present study focused on GC-triggered alterations in the mRNA expression of surface glycosylation regulators, as well as key components of signaling pathways responsible for cell-extracellular matrix adhesion, neovascularization and invasion, each of which contribute to the metastatic potential of cancer cells. The GCs assessed included GlcNAc moieties linked with a calix[4]arene or with a polyamidoamine dendrimer (PAMAM) core. Calix[4]arenes possessing distinctive geometry act as carriers of anticancer drugs (12) or as direct anticancer agents via enzyme inhibition (13), angiogenesis inhibition (14) or innate immunity modulation (15). PAMAM dendrimers have previously been used to deliver genes and drugs (16).

Cells internalize exogenous glucosamine via the glucose transporter and process it, as well as cellular glucosamine, via lysosomal degradation into uridine diphosphate glucose (UDP)-GlcNAc $(17,18)$. This UDP-GlcNAc is further used in the post-transcriptional modification of glycosylate substrates, such as proteins. Glycosylation of nuclear proteins, including histone $\mathrm{H} 2 \mathrm{~B}$, contributes to transcriptional regulation (19). The genes encoding the sodium glucose cotransporter 1 (Sglt1) and epidermal growth factor receptor (Egfrl) are components of a glucose co-transporter. Sglt1 is expressed primarily in the human intestine and kidney (20). An example of a Egfrl ligand is $N$-acetylglucosamine (21). Glycosylation of the epidermal growth factor receptor improves its ability to bind to epidermal growth factor (22). The coupling of Egfrl to Sglt1 further stabilizes the whole complex and enables cancer cells to take up high levels of glucose (23).

The authors of the present study previously reported that a GC consisting of four GlcNAc residues on a $N$-acetyl-D-glucosamine-coated calix[4]arene core (GN4C) alters the glycosylation of human NK cells and promotes the cell-mediated cytotoxicity of human NK cells against K562 and HT-29 target cells via the phosphoinositide 3-kinase pathway (2). In addition, it has been demonstrated that a GC consisting of eight GlcNAc residues on a PAMAM core $\mathrm{N}$-acetyl-D-glucosamine-coated polyamidoamine dendrimer (GN8P) mediates alterations in cytokine profile specific to mouse NK T-cells and macrophages (24). Therefore, the present study aimed to determine whether these GCs directly affect cancer cells by modulating the regulation of gene expression and causing changes in the phenotypes of malignant cells. The effect of synthetic GCs on the mRNA expression of the cell glucosaminyltransferases Mgat3 and Mgat5, members of the Wnt signaling family ( $W n t 2 B$ and $W n t 9 B)$, regulators of glucose metabolism (Sgltl and $E g f r l)$ and regulators of cell adhesion and invasion matrix metalloproteinase $3(\mathrm{Mmp3})$ or transforming growth factor- $\beta 1$ (Tgfbl) were measured.

\section{Materials and methods}

Preparation and treatment of cells with GCs. The HT-29 adenocarcinoma cell line (ATCC number: HTB-38) was obtained from American Type Culture Collection (Manassas,
VA, USA) and was authenticated following the guidelines of the International Cell Line Authentication Committee (https://www.lgcstandards-atcc.org). Cells were maintained in $37^{\circ} \mathrm{C}$ and in an RPMI-1640 medium with $10 \%$ fetal calf serum (Sigma-Aldrich, Merck KGaA, Darmstadt, Germany). Peripheral blood mononuclear cells (PBMC) were obtained from peripheral blood of healthy donors (4 males, mean age 46.3 \pm 9.4 ; samples collected August 2012) using a Ficoll-Paque (GE Healthcare Life Sciences, Little Chalfont, $\mathrm{UK}$ ) at density $1,077 \mathrm{~g} / \mathrm{ml}$ and centrifugation for $40 \mathrm{~min}$ at room temperature and $400 \mathrm{x}$ g. Blood samples were taken from material remaining following a routine donor check-up at the transfusion unit of the Thomayer Hospital (Prague, Czech Republic). All donors signed informed consent for the use of their blood for experimental purposes. The current study was approved by the Ethical Committee of Thomayer Hospital. The chemically defined GC calix[4]arene containing of four terminal N-acetyl-D-glucosamine moieties (GN4C) was synthesized and kindly provided by Vladimir Křen and Karel Křenek (Czech Academy of Sciences, Prague, Czech Republic). A GC consisting of PAMAM with eight terminal $\mathrm{N}$-acetyl-D-glucosamine moieties (GN8P) was synthesized and kindly provided by Thisbe Lindhorst (Christiana Albertina University, Kiel, Germany). The synthesis, purity, nuclear magnetic resonance data and dose-dependent effect of the GCs on human PBMC cells have been previously described (2,24-26). The optimal concentration of $10 \mathrm{nM}$ GN4C or GN8P were used for the experiments. Fludara ${ }^{\circledR}$ (1 mM, FLU; Genzyme, Cambridge, MA, USA), which is a conventional anticancer drug, was used to compare the anticancer effect of the tested GCs with a known anticancer agent.

Glyco-gene profiling array. The HT-29 cell line was incubated with GN8P for $24 \mathrm{~h}$ and total RNA was isolated using an RNAeasy Mini kit involving DNAse I treatment following the manufacturer's protocol (DNAse I was a component of RNAeasy Mini kit; Qiagen GmbH, Hilden, Germany). A Glyco-gene Chip array (GLYCOv3 Gene Chip; Affymetrix; Thermo Fisher Scientific, Inc., Waltham, MA, USA) containing probe sets of 2,000 human transcripts was provided by the Consortium for Functional Glycomics (http://www.functionalglycomics.org/static/consortium/resources/resourcecoree.shtml). Microarray experiments were conducted by The Microarray Gene Core of Consortium for Functional Glycomics, National Institutes of Health (NIH)/National Institute of General Medical Sciences (NIGMS), both Bethesda, MD, USA (http://www.functionalglycomics.org) and were performed in triplicate. BRB ArrayTools version 4.3.0 beta 3 [Biometric Research Branch, $\mathrm{NIH} /$ National Cancer Institute (NCI)] were used to filter and analyze experimental data sets. Class comparison used a two-sample t-test with a random variance model. A P-value of log-ratio $<0.05$ was considered significant.

Gene Ontology analysis was performed using the Database for Annotation, Visualization and Integrated Discovery (DAVID) software version 6.7 available from NCI (http://david.abcc.ncifcrf.gov). The Gene Card database was used for basic gene identification and characterization (http://www.genecards.org; Weizmann Institute of Science, Rehovot, Israel). 
Reverse transcription quantitative polymerase chain reaction (RT-qPCR). The HT-29 cell line was incubated with GCs and FLU for $24 \mathrm{~h}$ and total RNA was isolated using an RNAeasy Mini kit involving DNAse I treatment, as described by the manufacturer (Qiagen). A total of $5 \mu \mathrm{g}$ RNA was transcribed into cDNA using a cDNA Archive kit (Applied Biosystems; Thermo Fisher Scientific, Inc.). qPCR was performed using PowerSybr Green Master mix (Applied Biosystems; Thermo Fisher Scientific, Inc.) on an iCycler5 (Bio-Rad Laboratories, Inc., Hercules, CA, USA). PCR product specificity was analyzed by melt curve analysis. The cycling conditions recommended by the Master mix manufacturer were followed: initiation $95^{\circ} \mathrm{C} 10 \mathrm{~min}$ and 40 cycles of $95^{\circ} \mathrm{C} 15 \mathrm{sec}$ and $60^{\circ} \mathrm{C} 1 \mathrm{~min}$. The primers used for PCR were designed using Primer3 Input software version 0.4.0 (National Center for Biotechnology Information, Bethesda, MD, USA). The sequences of primers were as follows: Mgat5, forward, 5'-CTT CTTTCTTCCAGCACCTCAAC-3' and reverse, 5'-AAACAC ACAGTGCTTATTCTTAGGG-3'; Nme1, forward, 5'-ACC TTCATTGCGATCAAACC-3' and reverse, 5'-GGCCCTGAG TGCATGTATTT-3'; Siglec5, forward, 5'-CAAGTGCAGAAG TCGGTGAC-3' and reverse, 5'-GGGTCTCTGGCTTCACTC TT-3'; Siglec8, forward, 5'-TGCAACCCTCAGCTTCCATA-3' and reverse, 5'-ACTTCTTTGCTGGAGGGGTT-3'; Wnt9B, forward, 5'-TGGGCAGACTGTCATCACAT-3' and reverse, 5'-AACAAGGTTGGGGATGCTTG-3'. Sequences of the primers used to amplify B2M, Egfrl and Sglt1, Mki67, Mmp3, $T g f b l$ and $W n t 2 B$ were described previously (27-31): $B 2 M$, forward, 5'-GAGTATGCCTGCCGTGTG-3' and reverse, 5'-AATCCAAATGCGGCATCT-3'; Egfrl, forward, 5'-TTT CGATACCCAGGACCAAGCCACAGCAGG-3' and reverse, 5'-AATATTCTTGCTGGATGCGTT TCTGTA-3'; Sglt1, forward, 5'-TGGCAGGCCGAAGTATGGTGT-3' and reverse, 5'-ATGAATATGGCCCCCGAGAAGA-3'; Mki67, forward, 5'-GGAGGCAATATTACATAATTTCA-3' and reverse, 5'-CAGGGTCAGAAGAGAAGCTA-3'; $M m p 3$, forward, 5'-ATGCCCACTTTGATGATGATGAAC-3' and reverse, 5'-CCACGCCTGAAGGAAGAGATG-3'; $T g f b 1$, forward, 5'-TGACAGCAGGGATAACACACT-3' and reverse, 5'-GTA GGGGCAGGGCCCGAGGCA-3'; $W n t 2 B$, forward, 5'-CAC CTGCTGGCGTGCACTCTCAGA-3' and reverse, 5'-GGG CTTTGCAAGTATGGACGTCCACAGTA-3'. Primers for Mgat3 were obtained from SA Biosciences; Qiagen (product ID: PPH01058A). The expression of the genes of interest were normalized to that of the control gene $B 2 M$ and quantified using the $2-^{\Delta \Delta \mathrm{Cq}}$ method (32). Differences in the expression of genes between the untreated and GC-treated cells were evaluated using Bio-Rad iQ5 version 2.0 (Bio-Rad Laboratories, Inc.).

Cell proliferation and colony formation assays. To determine the effect of GCs on cell growth, $5 \times 10^{3}$ cells/well were seeded in triplicate on a 96-well plate and incubated with GCs for $126 \mathrm{~h}$. FLU (1 mM) was used as a positive control of tumor cell growth inhibition. Negative controls represent cells with no additional treatment. Cell growth was monitored continuously using a Real-Time Cell Analyzer (RTCA; xCELLigence System; Acea Biosciences, San Diego, CA, USA; https://www.aceabio. com/products/rtca-dp/) and evaluated using RTCA software version 1.2 (Acea Biosciences).
To study colony formation, a standard colony forming assay and an impedance-based assay using the RTCA instrument (Acea Biosciences) were performed. For colony formation assays, $1 \times 10^{3}$ were seeded in a Petri dish $100 \mathrm{~mm}$ in diameter. After 2 weeks, colonies were fixed for $30 \mathrm{~min}$ with $70 \%$ ethanol (Sigma-Aldrich; Merck KGaA) at room temperature and subsequently stained for $10 \mathrm{~min}$ at room temperature with $0.5 \%$ crystal violet (Sigma-Aldrich; Merck KGaA). RTCA was also used to evaluate colony growth in order to obtain quantitative data. Here, 100 cells/well were seeded in triplicate on a 96-well plate and colony growth was monitored using RTCA for 2 weeks.

Apoptosis assay and cell-mediated cytotoxicity test. GC-mediated toxicity in the HT-29 cancer cell line was assessed using propidium iodide (PI) staining and subsequent flow cytometry with a BD LSRII (BD Biosciences, Franklin Lakes, NJ, USA). Apoptosis was measured using an FITC Annexin V Apoptosis Detection kit I (Annexin V-fluorescein isothiocyanate, BD Biosciences) following the manufacturer's protocol. The results were analyzed using FlowJo version 7.2.2 software (FlowJo LLC, Ashland, OR, USA).

Cell-mediated cytotoxicity was performed using a standard chromium release assay, as previously described (2). Briefly, HT-29 cells ( $2 \times 10^{4}$ cells/well) pretreated with or without GCs for $30 \mathrm{~min}$ were incubated with ${ }^{51} \mathrm{Cr}$ for $2 \mathrm{~h}$ and served as target cells for PBMCs (total volume $0.1 \mathrm{ml} /$ well). All samples were tested in triplicate. The effector:target ratio of 16:1 was optimal for the experimental conditions. Following $4 \mathrm{~h}$ co-incubation of target and PBMC cells, ${ }^{51} \mathrm{Cr}$ release was measured in cell-free supernatants (obtained as supernatants following centrifugation of cells at 2,000 x $\mathrm{g}$ for $5 \mathrm{~min}$ at room temperature) using a Wallac Microbeta Trilux scintillation counter (PerkinElmer, Inc., Waltham, MA, USA). The percentage specific lysis was calculated using the following formula: [Experimental counts per minute (cpm) - spontaneous cpm $] /$ (maximum cpm - spontaneous cpm) x 100, where maximum cpm was determined by addition of $10 \%$ Triton X-100.

Statistical analysis. Statistically significant differences in the parameters tested in HT-29 cells cultured in the presence or absence of GCs were assessed using a one-way analysis of variance followed by Dunnett's post hoc test and a confidence interval of $95 \%$. Statistical analysis was conducted using GraphPad Prism 5 software (GraphPad Software, Inc., La Jolla, CA, USA). P $<0.05$ was considered to indicate a statistically significant difference.

\section{Results}

GC stimulation modulates the mRNA expression of glucosaminyltransferases, components of glucose metabolism and adhesion molecules. Previous research has noted alterations in the phenotype of cancer cells following treatment with GCs. Therefore, the present study investigated a wide range of candidate molecules and the results revealed that the interaction of cancer cells with GCs induced complex alterations in gene expression.

Candidate molecules were selected based on the novel results of a glyco-gene array investigating GN8P, as well 
Table I. List of GN8P-responsive genes in the HT-29 cell line.

\begin{tabular}{|c|c|c|c|c|}
\hline Gene & Entrez gene ID & Biological function & Disease association & (Refs.) \\
\hline \multicolumn{5}{|c|}{ Upregulated genes } \\
\hline$M p l$ & 4352 & GFR, ST, CP & CAMT, TR, PV, MD & $(33-35)$ \\
\hline Flt3 & 2322 & Ig, TK, ST, CP & C-L (AML, ALL) & $(36,37)$ \\
\hline Bmp7 & 655 & GF, TGF & $\mathrm{RD}, \mathrm{OS}, \mathrm{PA}$ & $(38-40)$ \\
\hline Ptprt & 11122 & ST, PP & $\mathrm{CoCa}$, glioma & $(41,42)$ \\
\hline$P p b p$ & 5473 & GF, GTTA, CP, I & IN, ET, TP & $(43-45)$ \\
\hline Cxcl2 & 2920 & $\mathrm{I}, \mathrm{CP}$ & $\mathrm{C}, \mathrm{N}, \mathrm{S}$ & $(46,47)$ \\
\hline$G p c 3$ & 2719 & $\mathrm{CP}$ & HepCa, WT & $(48,49)$ \\
\hline \multicolumn{5}{|c|}{ Downregulated genes } \\
\hline Siglec12 & 89858 & $\mathrm{CB}$, adheze & - & $(50)$ \\
\hline Nrgl & 3084 & $\mathrm{GF}, \mathrm{TF}$ & $\mathrm{C}, \mathrm{SC}$ & $(51)$ \\
\hline Ccl7 & 6354 & $\mathrm{I}, \mathrm{ST}$ & IN, AS & $(52)$ \\
\hline Lgals 13 & 29124 & CB, GAL, LPL & Pre-eclampsia & (53) \\
\hline Csf2ra & 1438 & ST, CP & $\mathrm{C}, \mathrm{N}$ & (54) \\
\hline Wnt9B & 7484 & ST & $\mathrm{C}$ & $(55)$ \\
\hline Clec $4 C$ & 170482 & $\mathrm{CB}, \mathrm{I}$ & - & $(56)$ \\
\hline$W n t 2 B$ & 7482 & ST & $\mathrm{C}$ & $(57)$ \\
\hline Mrcl & 4360 & $\mathrm{CB}, \mathrm{L}, \mathrm{RI}$ & TBC, ALL & $(58,59)$ \\
\hline Cxccl9 & 4283 & ST, I & $\mathrm{N}, \mathrm{IN}$ & $(60)$ \\
\hline Sgsh & 6448 & hydrolase, GB & MPS & (61) \\
\hline Clec $3 B$ & 7123 & $\mathrm{CB}, \mathrm{L}, \mathrm{PAP}$ & $\mathrm{C}$ & (62) \\
\hline$G d f 11$ & 10220 & TGF, GF & ALL & (63) \\
\hline$E m r 2$ & 30817 & ST & $\mathrm{CoCa}$ & (64) \\
\hline$H s 3 s t 5$ & 222537 & GB & $\mathrm{CoCa}$ & $(65)$ \\
\hline
\end{tabular}

CAMT, congenital amegakaryocytic thrombocytopenia; TR, thrombocytosis; PV, polycythemia vera; MPS, mucopolysaccharidosis; C-L, leukemia; MD, myeloproliferative disorders; OS, osteosarcoma; PA, pseudarthrosis; RD, renal disease; CoCa, colon cancer; HepCa, hepatocellular carcinoma; WT, Wilm's tumor; KS, Kaposhi sarcoma; SC, schizophrenia; IN, inflammation; ET, essential hypertension; TP, thrombocytopenia; C, cancer; N, necrosis; S, sepsis; DA, dermatitis atopic; AS, asthma; GFR, growth factor receptor; TK, tyrosin kinase; CP, cell proliferation; ST, signal transduction; GTTA, glucose transmembrane transporter activity; I, immune processes; CB, carbohydrate binding; T, transferase; GB, glycan biosynthesis; SFT, sulfotransferase; Ig, immunoglobulin protein domain; L, lectin pr dom; RI, ricin B lectin pro dom; GAL, galectin pr dom; PAP, pancreatis associated protein; TGF, transforming growth factor $\beta$ receptor binding; PP, protein tyrosine phosphatase activity; UDP, glucuronosyl/UDP glucosyl transferase; LPL, lysophospholipase activity.

as previously published results of glyco-gene profiling of GN4C in NK-92 cancer cells (2). Regarding the glyco-gene array performed on cell samples incubated for $24 \mathrm{~h}$ in the presence or absence of GN8P, the present study excluded all genes in which the percentage of absent data (all data where two out of three parallels were missing) $>50 \%$ and where $\mathrm{P}>0.05$. Subsequently, class comparison identified 22 genes that exhibited significantly different expression between control and GN8P-treated HT-29 cells $(\mathrm{P}<0.05)$. The responsive genes were functionally categorized according to Gene Ontology classification and the Gene Card database. A total of $64 \%$ of the genes listed were linked to cancer and $14 \%$ of the genes were linked to inflammation. Differentially expressed genes were primarily involved in signal transduction (28\%), carbohydrate binding (23\%), proliferation (14\%) and immune processes (14\%). A complete list of the differentially expressed genes, including their function and disease association, is presented in Table I. Along with other genes, GN8P mediated the downregulation of Wnt signaling molecules that serve an important role in cancer progression; thus inhibition of their expression is of particular interest. Upregulated genes included protein tyrosine phosphatase Ptprt and tyrosine kinase Flt3 (Table I). Candidate genes were validated by RT-qPCR (data not shown).

For a detailed examination of the effect of GCs on the glycosylation mechanism in HT-29 cells, the expression of glucosaminyltransferases involved in terminal glycan elongation and genes involved in glucose uptake and cell adhesion, were measured. When compared with the NTC group, treatment with the GN4C and GN8P significantly downregulated expression levels of $\operatorname{Mgat} 3(\mathrm{P}=0.0002$ and $\mathrm{P}=0.0001$, respectively) and Mgat5 (each, $\mathrm{P}=0.0001)$ glucosaminyltransferases. FLU also inhibited the expression of Mgat5 ( $\mathrm{P}=0.0001)$ compared with the NTC group. The Nmel gene encodes a transcription regulator controlling expression of the Mgat5 gene (9). Compared with the NTC group, the mRNA expression of this transcription factor was significantly downregulated by GN8P and FLU ( $\mathrm{P}=0.0009$ and $\mathrm{P}=0.002$, respectively; Fig. 1A). 
A

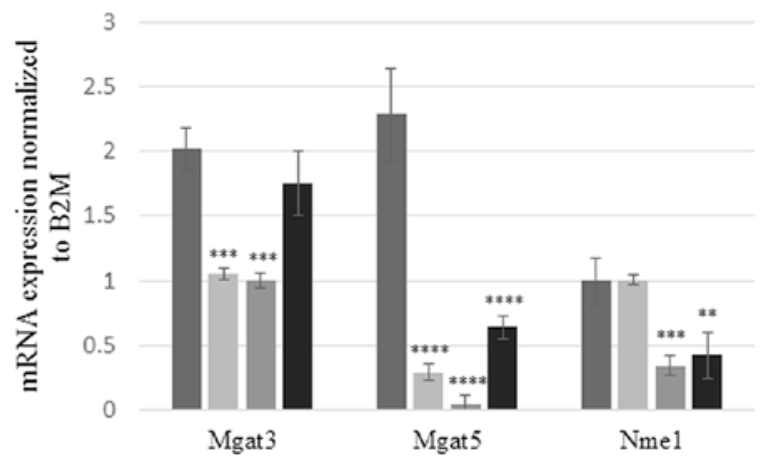

B

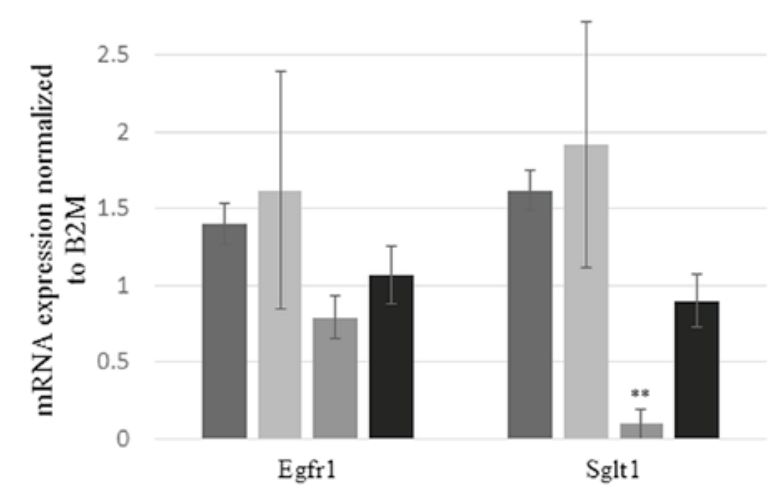

$\mathrm{C}$

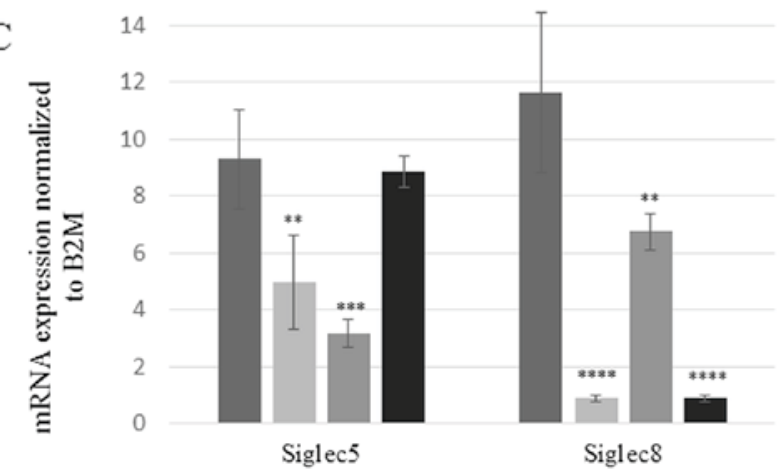

$=\mathrm{NTC} \equiv \mathrm{GN} 4 \mathrm{C}=\mathrm{GNSP} \boldsymbol{\mathrm { FLU }}$

Figure 1. Synthetic glycoconjugates modulate the mRNA expression of glycosylation regulators in colon cancer cells. Graphs present the mRNA expression (fold change) of (A) the glucosaminyltransferases Mgat3, Mgat5 and the transcription factor Nmel, (B) the glucose cotransporter components Egfrl and Sglt1 and (C) expression of the control B2M. Data are presented as the mean \pm standard deviation. Experiments were performed in triplicate. ${ }^{* *} \mathrm{P}<0.01,{ }^{* * * *} \mathrm{P}<0.001$ and ${ }^{* * * *} \mathrm{P}<0.0001$ vs. NTC group. NTC, non-treated control; GN4C and GN8P, cells treated with GN4C or GN8P, respectively; FLU, Fludara positive control treated cells; GN4C, $N$-acetyl-D-glucosamine-coated calix[4]arene; GN8P, $\mathrm{N}$-acetyl-D-glucosamine-coated polyamidoamine dendrimer.

Sglt1 and Egfrl are components of a glucose cotransporter in human cells. The mRNA expression of these genes was significantly reduced by GN8P ( $\mathrm{P}=0.0054$ for SGLT1). However, the reduction of EGFR1 expression following exposure to GN8P was of borderline significance $(\mathrm{P}=0.2)$ (Fig. 1B). Furthermore, the mRNA expression of the glycan binding adhesion molecules Siglec 5 and Siglec 8 were downregulated by $\mathrm{GN} 4 \mathrm{C}(\mathrm{P}=0.0078$ and $\mathrm{P}=0.0001$, respectively) as well as by GN8P ( $\mathrm{P}=0.0009$ and $\mathrm{P}=0.0081$, respectively; all Fig. 1C).
However, FLU only inhibited the mRNA expression of Siglec 8 ( $\mathrm{P}=0.0001$; Fig. 1C).

GCs inhibit HT-29 cell proliferation, induce apoptosis and promote PBMC-mediated cytotoxicity. The present study questioned whether GCs alter the proliferation of cancer cells. To test this hypothesis, real-time monitoring of cell proliferation was performed for 5 days. A proliferation protocol was optimized using an RTCA system allowing the continuous monitoring of treated and untreated cells for a set period of time. The results indicated that the proliferation of HT-29 cells treated with GN4C, GN8P or FLU was significantly inhibited from $\sim 5 \mathrm{~h}$ following induction. The greatest inhibition of cell growth was detected $60 \mathrm{~h}$ following treatment in the cells treated with FLU, GN8P and GN4C ( $\mathrm{P}=0.0001$ for all treatments vs. NTC group; Fig. 2A). A significant reduction in the expression of the proliferation antigen Mki67 $48 \mathrm{~h}$ following treatment with GN4C $(\mathrm{P}=0.0017), \mathrm{GN} 8 \mathrm{P}(\mathrm{P}=0.0005)$ and FLU ( $\mathrm{P}=0.0003$; Fig. 2B), was observed, compared with the NTC group.

To determine the toxicity of GCs in the HT-29 cell line, Annexin $\mathrm{V}$ positivity (specific marker of apoptosis) and the incorporation of PI into cells were measured. The percentage of early apoptotic, Annexin V-positive and PI-negative cells was significantly increased following treatment with GN4C, GN8P and FLU ( $\mathrm{P}=0.0001, \mathrm{P}=0.002$ and $\mathrm{P}=0.0001$, respectively), compared with the NTC group. Treatment with FLU induced a significant decrease in the population of cells in the late apoptotic and necrotic phases compared with the NTC group (all P=0.0001; Fig. 2C) However, treatment with GCs had no effect on the proportion of cells in the late apoptotic and necrotic stages of apoptosis (Fig. 2C). The proportion of untreated HT-29 cells that underwent spontaneous necrosis (PI positive, Annexin V-negative population) was 5.8\%; comparable with the percentage of necrotic cells found in GN4C and GN8P treated cells (Fig. 2C). These results indicate that GCs preferably induce apoptosis over necrosis.

Surface glycosylation is a tool facilitating the recognition of cancer cells by immune cells. The current study questioned whether alterations in cancer cell glycosylation sensitizes them to PBMC-mediated toxicity. HT-29 cells, acting as target cells, which were naturally resistant to human PBMC-mediated cytotoxicity, were pretreated with GCs and subsequently exposed to PBMCs from healthy donors, acting as effector cells. Significantly higher cytolytic activity was observed in HT-29 cells pretreated with GN4C and GN8P ( $\mathrm{P}=0.0002$ and $\mathrm{P}=0.0001$, respectively; Fig. 2D). The rate of spontaneous toxicity in untreated HT-29 cells against human PBMCs was $\sim 1.2 \%$ (Fig. 2D).

Synthetic GCs reduce cancer cell colony formation. As cell invasion is associated with extracellular matrix remodeling and neoangiogenesis, levels of regulatory components, including $M m p 3, T g f b 1, W n t 2 B$ and $W n t 9 B$, were measured. There was a significant decrease in the expression of Mmp3 mRNA following treatment with GN4C and FLU $(\mathrm{P}=0.0005$ and $\mathrm{P}=0.0006$, respectively; Fig. $3 \mathrm{~A})$. GN4C inhibited the expression of $T g f b 1$ ( $\mathrm{P}=0.0016$; Fig. 3A). GN4C and GN8P decreased the expression of $\operatorname{Wnt} 2 B(\mathrm{P}=0.0002$ and $\mathrm{P}=0.0066$, respectively $)$ and $W n t 9 B(\mathrm{P}=0.0004$ and $\mathrm{P}=0.0101$, 

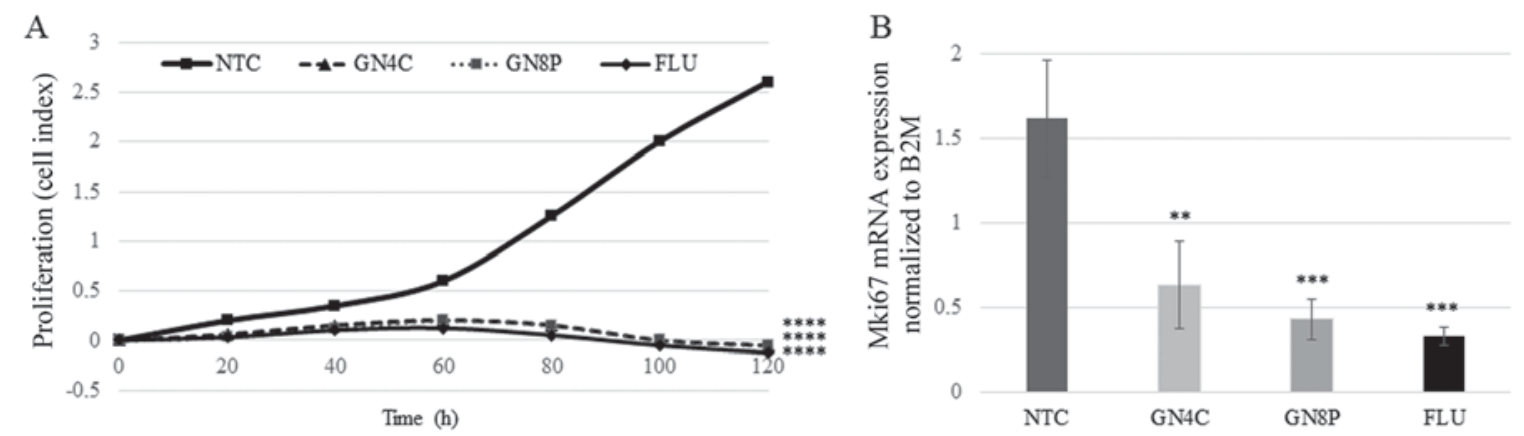

$$
\mathrm{C}
$$

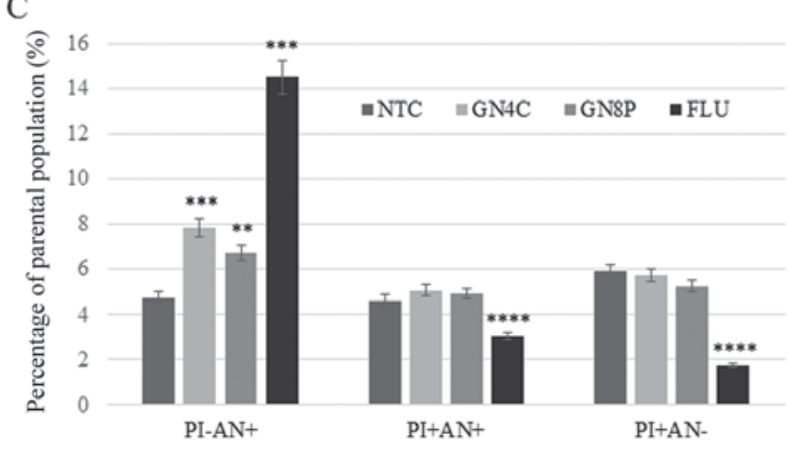

$\mathrm{D}$

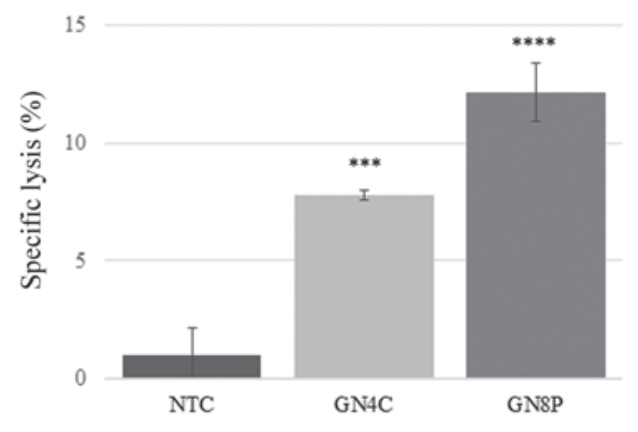

Figure 2. Effect of synthetic glycoconjugates on cell proliferation, apoptosis and sensitivity to cell-mediated killing. (A) Proliferation curve of cancer cells measured using a Real-Time Cell analyzer. The cell index reflects the number of live, attached cells. Average values of triplicates are plotted. (B) mRNA expression (fold change) of the proliferative antigen Mki67. (C) Detection of apoptotic and necrotic cells by flow cytometric analysis. The early apoptotic population was represented by cells that were PI- and AN+; the late apoptotic population was represented by cells that were PI+ and AN+; the necrotic population was represented by cells that were PI+ and AN-. (D) The cell mediated cytotoxicity assay employed PBMCs. Data are presented as the mean \pm standard deviation. Experiments were performed in triplicate. ${ }^{* *} \mathrm{P}<0.01,{ }^{* * *} \mathrm{P}<0.001$ and ${ }^{* * * * *} \mathrm{P}<0.0001$ vs. NTC control group. PBMCs, peripheral blood mononuclear cells; NTC, glycoconjugate-non-treated control with basic toxicity of PBMC to HT-29 cancer cells; GN4C and GN8P, cells treated with GN4C or GN8P, respectively; FLU, cells treated with Fludara that represented the positive control; GN4C, $N$-acetyl-D-glucosamine-coated calix[4]arene; GN8P, $N$-acetyl-D-glucosamine-coated polyamidoamine dendrimer; PI, propidium iodide; AN, Annexin V; +, positive; -, negative.
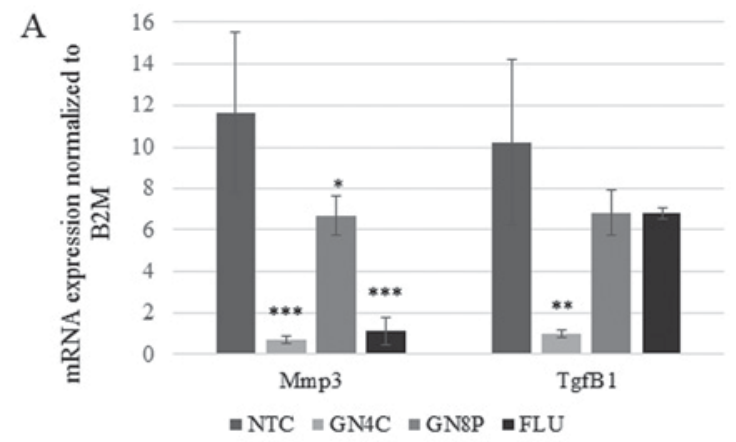

C

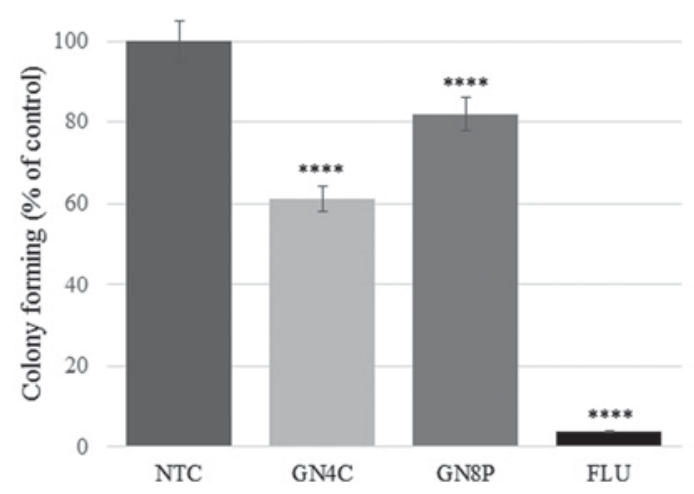

B

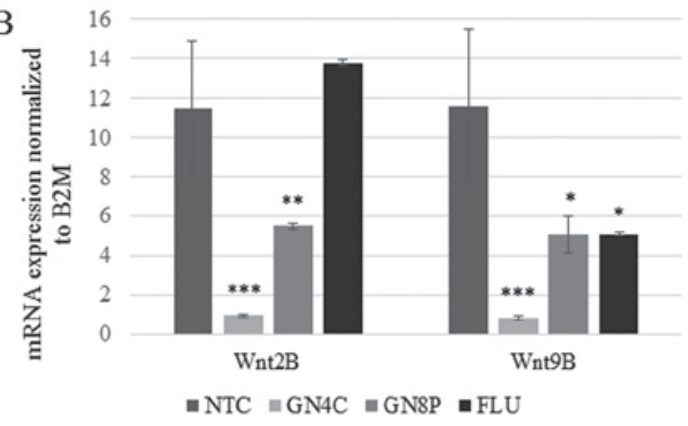

$\mathrm{D}$

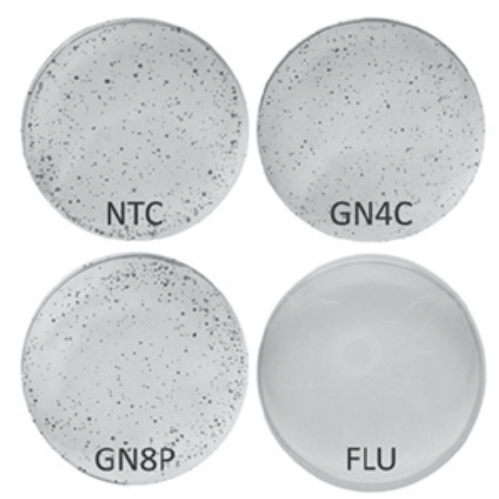

Figure 3. Colony forming inhibition triggered by glycoconjugates associated with altered expression of cell invasion regulators. Fold change in mRNA expression of the cell invasion and migration regulators (A) $M m p 3$ and $T g f b l$ and (B) Wnt2B and Wnt9B. (C) Inhibition of colony formation measured in real-time. The proportion of inhibition compared with the non-treated control cells is presented. (D) Conventional colony formation assay. Representative images are presented. Data are presented as the mean \pm standard deviation. Experiments were performed in triplicate. ${ }^{*} \mathrm{P}<0.05,{ }^{* * *} \mathrm{P}<0.01,{ }^{* * * *} \mathrm{P}<0.001$ and ${ }^{* * * * *} \mathrm{P}<0.0001$ vs. NTC group. NTC, non-treated control; GN4C and GN8P, cells treated with GN4C or GN8P, respectively; FLU, positive control cells treated with Fludara; GN4C, $N$-acetyl-D-glucosamine-coated calix[4]arene; GN8P, $N$-acetyl-D-glucosamine-coated polyamidoamine. 
respectively; Fig. 3B). FLU significantly decreased the expression of Wnt $9 B(\mathrm{P}=0.01$; Fig. 3B) but not Wnt $2 B$. Treatment of HT-29 cells with GN4C and GN8P led to decreases in cell colony formation by 39 and $18 \%$, respectively $(\mathrm{P}=0.0001 \mathrm{vs}$. NTC). FLU treated (positive control) cells exhibited a decrease in cell colony formation of $96 \%$ compared with the NTC group ( $\mathrm{P}=0.0001$; Fig. 3C). These changes in colony formation were confirmed following standard crystal-violet staining. There was a reduction in colonies in samples incubated with GCs and FLU (Fig. 3D).

\section{Discussion}

Previous studies have focused on the identification of genes involved in the response of NK cells isolated from PBMC and the permanent NK-92 cell line to the synthetic GC GN4C (2), or on the role of GN8P in the activation of immune cells (24).

Phenotypic alterations in cancer cells following exposure to GCs has been observed. Calix[6]arenes exhibit an anticancer effect by modulating AXL and Mer tyrosine kinase receptor gene expression (66); therefore, the present study questioned whether the phenotypic changes in cancer cells were modulated by changes in gene expression. The current study specifically focused on the expression of cancer development-related genes and how gene expression is affected by two GlcNAc-modified GCs that contain different cores: First generation PAMAM or calix[4]arene.

Previous studies have reported that exogenous glucosamine, the terminal moiety of the tested GCs, may be internalized via a glucose transporter $(17,18)$. In HT-29 cells, clathrin-mediated endocytosis has been described as a mechanism of uptake of third generation PAMAM (67). Cancer cells, such as HT-29, exhibit a high glucose intake due to high-energy requirements (22). The sodium-glucose cotransporter (SGLT1) transports glucose into cells independent of its concentration (68). SGLT1 is stabilized by interaction with EGFR1, facilitating cancer cell survival (27). In colon cancer, the high expression of Sglt1 and Egfrl is associated with poor patient prognosis (69). The results of the present study demonstrated that the PAMAM-based GC significantly decreased the expression of the two genes Sgltl and Egfrl that code for the glucose cotransporter complex. This, in turn, inhibited cell growth and reduced levels of the proliferation antigen Mki67.

It has been reported that higher generation dendrimers (G2, G4 and G6) promote cell growth at lower concentrations but induce cell death at higher concentrations. The critical concentration at which dendrimers induced cell death was $500 \mathrm{nM}$. Also, toxicity was enhanced by higher generation dendrimers (70). The current study observed that a first generation PAMAM dendrimer with eight GlcNAc moieties induced alterations in gene expression and altered the properties of cancer cells even at low concentrations $(10 \mathrm{nM})$. Comparing the responses of cells to GCs and FLU identified the different underlying mechanisms of action of each compound. FLU is a potent inducer of apoptosis and affected cells undergo rapid disintegration, thus explaining the decrease in the number of cells in the late apoptotic and necrotic phases following treatment with FLU.

The growth of cancer cells was markedly affected by the GC GN8P and changes in cell adhesion and invasion were associated with the altered expression of specific mRNAs. The Siglec family contains proteins that serve an important role in cancer cell adhesion and invasion. Human cell-surface-receptors, including sialic acid-binding Ig-like lectin (SIGLEC) 5 and SIGLEC8, are members of the cluster of differentiation 33-related Siglec subfamily, expressed predominantly by immune cells (71) and they are overexpressed in acute myeloid leukemia, chronic eosinophilic and myelogenous leukemias $(72,73)$. In solid tumors, Siglecs are overexpressed in tumor-associated immune cells, such as macrophages; however there is little evidence regarding their overexpression in actual cancer cells (74). The alteration in Siglec mRNA expression observed in the present study following the incubation of tumor cells with GC may be due to alterations in Mgat5 expression.

In colon cancer, glycosylation performed by MGAT5 may regulate colon cancer stem cells and tumor progression via Wnt signaling (75). As GCs downregulate the expression of Mgat5 and exhibit reduced colony formation, the present study measured the expression of the Wnt family members Wnt $2 B$ and $W n t 9 B$, the metalloproteinase $M m p 3$, which is responsible for extracellular matrix remodeling (76) and $T g f b 1$, which is involved in tumor neoangiogenesis (77). These genes were selected based on the preliminary results of cDNA profiling in GN8P-treated cancer cells (unpublished results). GCs reduced the expression of $W n t 2 B$ and $W n t 9 B$; however, only GN4C inhibited the expression of $M m p 3$ and $\mathrm{Tg} f b l$. This may be due to the fact GN4C is more effective at inhibiting cell invasion; indeed, it has been demonstrated that calix[4]arene inhibits cancer angiogenesis (78).

The present study identified a specific pattern in gene expression, common to the two GCs, which included downregulation of i) the glucosaminyltransferases Mgat3 and Mgat5, ii) the adhesion molecules Siglec5 and Siglec8, iii) $W n t 2 B$ and $W n t 9 B$ and iv) the proliferation marker Mki67. The two GCs increased the proportion of cells in the early apoptotic phase and the sensitivity of cancer cells to PBMCs. The current study focused the effect of GCs in cancer cells and revealed associations that may allow for the investigation of individual components in a different perspective or focus on specific signaling pathways induced by the GCs. It has been demonstrated that glycosylation in NK cells involves the phosphoinositide 3-kinase signaling pathway (2). Based on information from a recently published report (79), alterations regarding the sensitivity to PBMCs may be due to the GlcNAc section of the GCs. In the case of the downregulation of the Sglt1/Egfrl, the PAMAM core may induce this change since GN8P significantly lowered expression of the Sglt1 component but GN4C demonstrated no such effect. In myotubes, Wnt signaling affects glucose transport via a glucose transporter (80). In the present study, the same members of the Wnt pathway (Wnt2B and Wnt9B) were downregulated by GN4C. No differences in $S g l t 1 / E g f r l$ expression following treatment with GN4C were detected. This suggests that these factors are not involved in colon cancer cell signaling, however, further analysis may reveal if there is a similar association between the SGLT1/EGFR1 cotransporter and other members of Wnt pathway.

It is likely that other members of the Wnt signaling pathway are involved and responsible for this distinctive 
response to particular cores. The present study demonstrated that Wnt signaling may be involved in the response of cancer cells to synthetic GCs, possibly via modulation of glucosaminyltransferases. Subsequent detailed studies focusing on the Wnt pathway may identify response-specific members of the Wnt family.

The evolutionarily conserved Wnt signaling mechanism is an important pathway and Wnt proteins undergo post-translational glycosylation. Therefore, anticancer therapies that target Wnt-signaling members, based on glycosylation modulation, may be developed as a novel therapeutic strategy.

In conclusion, the present study demonstrated that the interaction of colon cancer cells with specifically designed GCs results in a complex commitment of different cellular pathways and induces alterations in the phenotypes of cells. The results of the current study revealed that alterations in the expression of particular genes following treatment with GCs are associated with specific outcomes in cancer cells, including their higher sensitivity to immune cell-mediated killing. The GCs used in the current study exhibited multiple effects following their application to cancer cells. These results, together with those of previous studies determining the immunostimulatory effects of GCs, support the importance of glycosylation-targeted anticancer therapy and provides a basis for further studies.

\section{Acknowledgements}

The authors wish to thank The Consortium for Functional Glycomics/NIGMS/Gene Microarray Core (grant no. GM62116) for their resources and collaboration. The authors thank Cory Benson for editing the English language of the manuscript, Professors Vladimır Křen and Thisbe Lindhorst for providing GCs and Dr Lucie Vondráčková for providing the xCELLigence system. The present study was supported by the Ministry of Health of the Czech Republic (grant no. 15-33094A) and the Czech Science Foundation (grant no. 14-10100S).

\section{References}

1. Kobata A and Amano J: Altered glycosylation of proteins produced by malignant cells and application for the diagnosis and immunotherapy of tumours. Immunol Cell Biol 83: 429-439, 2005.

2. Benson V, Grobarova V, Richter J and Fiserova A: Glycosylation regulates NK cell-mediated effector function through PI3K pathway. Int Immunol 22: 167-177, 2010.

3. Lau E, Feng Y, Claps G, Fukuda MN, Perlina A, Donn D, Jilaveanu L, Kluger H, Freeze HH and Ronai ZA: The transcription factor ATF2 promotes melanoma metastasis by suppressing protein fucosylation. Sci Signal 8: ra124, 2015.

4. Pinho SS and Reis CA: Glycosylation in cancer: Mechanisms and clinical implications. Nat Rev Cancer 15: 540-555, 2015.

5. Cipolla L, La Ferla B and Gregori M: Combinatorial approaches to iminosugars as glycosidase and glycosyltransferase inhibitors. Comb Chem High Throughput Screen 9: 571-582, 2006.

6. Abbott KL, Nairn AV, Hall EM, Horton MB, McDonald JF, Moremen KW, Dinulescu DM and Pierce M: Focused glycomic analysis of the N-linked glycan biosynthetic pathway in ovarian cancer. Proteomics 8: 3210-3220, 2008.

7. Kang X, Wang N, Pei C, Sun L, Sun R, Chen J and Liu Y: Glycan-related gene expression signatures in human metastatic hepatocellular carcinoma cells. Exp Ther Med 3: 415-422, 2012.

8. Song Y, Aglipay JA, Bernstein JD, Goswami S and Stanley P: The bisecting GlcNAc on N-glycans inhibits growth factor signaling and retards mammary tumor progression. Cancer Res 70: 3361-3371, 2010.
9. Chakraborty AK, Sousa Jde F, Chakraborty D, Funasaka Y, Bhattacharya M, Chatterjee A and Pawelek J: GnT-V expression and metastatic phenotypes in macrophage-melanoma fusion hybrids is down-regulated by 5-Aza-dC: Evidence for methylation sensitive, extragenic regulation of GnT-V transcription. Gene 374: 166-173, 2006.

10. Lau KS and Dennis JW: N-Glycans in cancer progression. Glycobiology 18: 750-760, 2008.

11. Yoshinaga A, Kajiya N, Oishi K, Kamada Y, Ikeda A, Chigwechokha PK, Kibe T, Kishida M, Kishida S and Komatsu M: NEU3 inhibitory effect of naringin suppresses cancer cell growth by attenuation of EGFR signaling through GM3 ganglioside accumulation. Eur J Pharmacol 782: 21-29, 2016.

12. Galindo-Murillo R, Sandoval-Salinas ME and Barroso-Flores J: In Silico design of monomolecular drug carriers for the tyrosine kinase inhibitor drug imatinib based on calix- and thiacalix [n] arene host molecules: A DFT and molecular dynamics study. J Chem Theory Comput 10: 825-834, 2014.

13. Cherenok S, Vovk A, Muravyova I, Shivanyuk A, Kukhar V, Lipkowski J and Kalchenko V: Calix[4]arene alpha-aminophosphonic acids: Asymmetric synthesis and enantioselective inhibition of an alkaline phosphatase. Org Lett 8: 549-552, 2006.

14. Zhou H, Wang DA, Baldini L, Ennis E, Jain R, Carie A, Sebti SM and Hamilton AD: Structure-activity studies on a library of potent calix[4]arene-based PDGF antagonists that inhibit PDGF-stimulated PDGFR tyrosine phosphorylation. Org Biomol Chem 4: 2376-2386, 2006.

15. Geraci C, Consoli GM, Galante E, Bousquet E, Pappalardo M and Spadaro A: Calix[4]arene decorated with four Tn antigen glycomimetic units and P3CS immunoadjuvant: Synthesis, characterization and anticancer immunological evaluation. Bioconjug Chem 19: 751-758, 2008.

16. Esfand R and Tomalia DA: Poly(amidoamine) (PAMAM) dendrimers: From biomimicry to drug delivery and biomedical applications. Drug Discov Today 6: 427-436, 2001.

17. Schleicher ED and Weigert C: Role of the hexosamine biosynthetic pathway in diabetic nephropathy. Kidney Int Suppl 77: S13-S18, 2000.

18. Hinderlich S, Berger M, Schwarzkopf M, Effertz K and Reutter W: Molecular cloning and characterization of murine and human $N$-acetylglucosamine kinase. Eur J Biochem 267: 3301-3308, 2000.

19. Phatnani HP and Greenleaf AL: Phosphorylation and functions of the RNA polymerase II CTD. Genes Dev 20: 2922-2936, 2006.

20. Gorboulev V, Schürmann A, Vallon V, Kipp H, Jaschke A, Klessen D, Friedrich A, Scherneck S, Rieg T, Cunard R, et al: $\mathrm{Na}^{+}$-D-glucose cotransporter SGLT1 is pivotal for intestinal glucose absorption and glucose-dependent incretin secretion. Diabetes 61: 187-196, 2012.

21. Ferguson KM, Berger MB, Mendrola JM, Cho HS, Leahy DJ and Lemmon MA: EGF activates its receptor by removing interactions that autoinhibit ectodomain dimerization. Mol Cell 11: 507-517, 2003.

22. Wang XQ, Sun P, O'Gorman M, Tai T and Paller AS: Epidermal growth factor receptor glycosylation is required for ganglioside GM3 binding and GM3-mediated suppression (correction of suppresion) of activation. Glycobiology 11: 515-522, 2001.

23. Hanahan D and Weinberg RA: Hallmarks of cancer: The next generation. Cell 144: 646-674, 2011.

24. Grobárová V, Benson V, Rozbeský D, Novák P and Cerný J: Re-evaluation of the involvement of NK cells and C-type lectin-like NK receptors in modulation of immune responses by multivalent GlcNAc-terminated oligosaccharides. Immunol Lett 156: 110-117, 2013.

25. Krenek K, Kuldová M, Hulíková K, Stibor I, Lhoták P, Dudic M, Budka J, Pelantová H, Bezouska K, Fiserová A and Kren V: $\mathrm{N}$-acetyl-D-glucosamine substituted calix[4]arenes as stimulators of NK cell-mediated antitumor immune response. Carbohydr Res 342: 1781-1792, 2007.

26. Vannucci L, Fiserová A, Sadalapure K, Lindhorst TK, Kuldová M, Rossmann $\mathrm{P}$, Horváth $\mathrm{O}, \mathrm{Kren} \mathrm{V}$, Krist $\mathrm{P}$, Bezouska $\mathrm{K}$, et al: Effects of $N$-acetyl-glucosamine-coated glycodendrimers as biological modulators in the B16F10 melanoma model in vivo. Int J Oncol 23: 285-296, 2003.

27. Weihua Z, Tsan R, Huang WC, Wu Q, Chiu CH, Fidler IJ and Hung MC: Survival of cancer cells is maintained by EGFR independent of its kinase activity. Cancer Cell 13: 385-393, 2008. 
28. Han Y, San-Marina S, Yang L, Khoury H and Minden MD: The zinc finger domain of Wilms' tumor 1 suppressor gene (WT1) behaves as a dominant negative, leading to abrogation of WT1 oncogenic potential in breast cancer cells. Breast Cancer Res 9: R43, 2007.

29. Ullmannová V, Stöckbauer P, Hradcová M, Soucek J and Haskovec C: Relationship between cyclin D1 and p21 Waf1/Cip during differentiation of human myeloid leukemia cell lines. Leuk Res 27: 1115-1123, 2003

30. Klatt AR, Paul-Klausch B, Klinger G, Kühn G, Renno JH, Banerjee M, Malchau $\mathrm{G}$ and Wielckens K: A critical role for collagen II in cartilage matrix degradation: Collagen II induces pro-inflammatory cytokines and MMPs in primary human chondrocytes. J Orthop Res 27: 65-70, 2009.

31. Van Den Berg DJ, Sharma AK, Bruno E and Hoffman R: Role of members of the Wnt gene family in human hematopoiesis. Blood 92: 3189-3202, 1998

32. Livak KJ and Schmittgen TD: Analysis of relative gene expression data using real-time quantitative PCR and the $2^{-\Delta \Delta C \mathrm{~T}}$ method Methods 25: 402-408, 2001.

33. Besancenot R, Roos-Weil D, Tonetti C, Abdelouahab H, Lacout C, Pasquier F, Willekens C, Rameau P, Lecluse Y, Micol JB, et al: JAK2 and MPL protein levels determine TPO-induced megakaryocyte proliferation vs differentiation. Blood 124: 2104-2115, 2014.

34. Moliterno AR, Hankins WD and Spivak JL: Impaired expression of the thrombopoietin receptor by platelets from patients with polycythemia vera. N Engl J Med 338: 572-580, 1998

35. Moliterno AR, Williams DM, Rogers O and Spivak JL: Molecular mimicry in the chronic myeloproliferative disorders: Reciprocity between quantitative JAK2 V617F and Mpl expression. Blood 108: 3913-3915, 2006.

36. Marhäll A, Kazi JU and Rönnstrand L: The Src family kinase LCK cooperates with oncogenic FLT3/ITD in cellular transformation. Sci Rep 7: 13734, 2017.

37. Rousset $\mathrm{D}$, Agnès $\mathrm{F}$, Lachaume $\mathrm{P}$, André $\mathrm{C}$ and Galibert $\mathrm{F}$ : Molecular evolution of the genes encoding receptor tyrosine kinase with immunoglobulinlike domains. J Mol Evol 41: 421-429, 1995.

38. Higgins DF, Ewart LM, Masterson E, Tennant S, Grebnev G, Prunotto M, Pomposiello S, Conde-Knape K, Martin FM and Godson C: BMP7-induced-Pten inhibits Akt and prevents renal fibrosis. Biochim Biophys Acta 1863: 3095-3104, 2017.

39. Anticevic D, Jelic M and Vukicevic S: Treatment of a congenital pseudarthrosis of the tibia by osteogenic protein-1 (bone morphogenetic protein-7): A case report. J Pediatr Orthop B 15: 220-221, 2006

40. Honda Y, Knutsen R, Strong DD, Sampath TK, Baylink DJ and Mohan S: Osteogenic protein-1 stimulates mRNA levels of BMP-6 and decreases mRNA levels of BMP-2 and -4 in human osteosarcoma cells. Calcif Tissue Int 60: 297-301, 1997.

41. Zhao Y, Scott A, Zhang P, Hao Y, Feng X, Somasundaram S, Khalil AM, Willis $\mathrm{J}$ and Wang Z: Regulation of paxillinp130-PI3K-AKT signaling axis by Src and PTPRT impacts colon tumorigenesis. Oncotarget 8: 48782-48793, 2017.

42. Bourgonje AM, Verrijp K, Schepens JT, Navis AC, Piepers JA, Palmen CB, van den Eijnden M, Hooft van Huijsduijnen R, Wesseling P, Leenders WP and Hendriks WJ: Comprehensive protein tyrosine phosphatase mRNA profiling identifies new regulators in the progression of glioma. Acta Neuropathol Commun 4: 96, 2016

43. Yeo L, Adlard N, Biehl M, Juarez M, Smallie T, Snow M, Buckley CD, Raza K, Filer A and Scheel-Toellner D: Expression of chemokines CXCL4 and CXCL7 by synovial macrophages defines an early stage of rheumatoid arthritis. Ann Rheum Dis 75: 763-771, 2016.

44. Sullam PM, Frank U, Yeaman MR, Täuber MG, Bayer AS and Chambers HF: Effect of thrombocytopenia on the early course of streptococcal endocarditis. J Infect Dis 168: 910-914, 1993.

45. Aziz H, Zaas A and Ginsburg GS: Peripheral blood gene expression profiling for cardiovascular disease assessment. Genomic Med 1: 105-112, 2007

46. De Plaen IG, Han XB, Liu X, Hsueh W, Ghosh S and May MJ: Lipopolysaccharide induces CXCL2/macrophage inflammatory protein-2 gene expression in enterocytes via NF-kappaB activation: Independence from endogenous TNF-alpha and platelet-activating factor. Immunology 118: 153-163, 2006.

47. Sarvaiya PJ, Guo D, Ulasov I, Gabikian P and Lesniak MS: Chemokines in tumor progression and metastasis. Oncotarget 4 2171-2185, 2013
48. Wang HL, Anatelli F, Zhai QJ, Adley B, Chuang ST and Yang XJ: Glypican-3 as a useful diagnostic marker that distinguishes hepatocellular carcinoma from benign hepatocellular mass lesions. Arch Pathol Lab Med 132: 1723-1728, 2008.

49. Tretiakova M, Zynger DL, Luan C, Andeen NK, Finn LS, Kocherginsky M, Teh BT and Yang XJ: Glypican 3 overexpression in primary and metastatic Wilms tumors. Virchows Arch 466: 67-76, 2015.

50. Mitra N, Banda K, Altheide TK, Schaffer L, Johnson-Pais TL, Beuten J, Leach RJ, Angata T, Varki N and Varki A: SIGLEC12, a human-specific segregating (pseudo)gene, encodes a signaling molecule expressed in prostate carcinomas. J Biol Chem 286: 23003-23011, 2011

51. Marballi K, Quinones MP, Jimenez F, Escamilla MA, Raventós H, Soto-Bernardini MC, Ahuja SS and Walss-Bass C: In vivo and in vitro genetic evidence of involvement of neuregulin 1 in immune system dysregulation. J Mol Med 88: 1133-1141, 2010.

52. Girkin J, Hatchwell L, Foster P, Johnston SL, Bartlett N, Collison A and Mattes J: CCL7 and IRF-7 mediate hallmark inflammatory and IFN responses following rhinovirus $1 \mathrm{~b}$ infection. J Immunol 194: 4924-4930, 2015.

53. Than NG, Romero R, Xu Y, Erez O, Xu Z, Bhatti G, Leavitt R, Chung TH, El-Azzamy H, LaJeunesse C, et al: Evolutionary origins of the placental expression of chromosome 19 cluster galectins and their complex dysregulation in preeclampsia. Placenta 35: 855-865, 2014.

54. Waghray M, Yalamanchili M, Dziubinski M, Zeinali M, Erkkinen M, Yang H, Schradle KA, Urs S, Pasca Di Magliano M, Welling TH, et al: GM-CSF mediates mesenchymal-epithelial cross-talk in pancreatic cancer. Cancer Discov 6: 886-899, 2016.

55. Akpa MM, Iglesias DM, Chu LL, Cybulsky M, Bravi C and Goodyer PR: Wilms tumor suppressor, WT1, suppresses epigenetic silencing of the $\beta$-catenin gene. J Biol Chem 290: 2279-2288, 2015.

56. Riboldi E, Daniele R, Parola C, Inforzato A, Arnold PL, Bosisio D, Fremont DH, Bastone A, Colonna M and Sozzani S: Human C-type lectin domain family 4, member C (CLEC4C/BDCA-2/ CD303) is a receptor for asialo-galactosyl-oligosaccharides. J Biol Chem 286: 35329-35333, 2011.

57. Shi Q, Liu H, Han P, Li C, Wang Y, Wu W, Zhu D, Amos CI, Fang S, Lee JE, et al: Genetic variants in $W N T 2 B$ and $B T R C$ predict melanoma survival. J Invest Dermatol 137: 1749-1756, 2017.

58. Lin SY, Li K, Stewart GS and Elledge SJ: Human Claspin works with BRCA1 to both positively and negatively regulate cell proliferation. Proc Natl Acad Sci USA 101: 6484-6489, 2004

59. Focarelli ML, Soza S, Mannini L, Paulis M, Montecucco A and Musio A: Claspin inhibition leads to fragile site expression. Genes Chromosomes Cancer 48: 1083-1090, 2009.

60. Ohta K, Shigeishi H, Taki M, Nishi H, Higashikawa K, Takechi M and Kamata N: Regulation of CXCL9/10/11 in oral keratinocytes and fibroblasts. J Dent Res 87: 1160-1165, 2008.

61. Sidhu NS, Schreiber K, Pröpper K, Becker S, Usón I, Sheldrick GM, Gärtner J, Krätzner R and Steinfeld R: Structure of sulfamidase provides insight into the molecular pathology of mucopolysaccharidosis IIIA. Acta Crystallogr D Biol Crystallogr 70: 1321-1335, 2014.

62. Zhang X, Wan JX, Ke ZP, Wang F, Chai HX and Liu JQ TMEM 88, CCL14 and CLEC3B as prognostic biomarkers for prognosis and palindromia of human hepatocellular carcinoma. Tumour Biol 39: 1010428317708900, 2017.

63. Yu H, Gaochao Z, Huaquan W, Limin X, Lijuan L, Huijuan J, Wei Z, Jinglian T and Zonghong S: GDF11 is increased in patients with myelodysplastic syndrome. Int J Clin Exp Pathol 9: 6031-6038, 2016

64. Safaee M, Ivan ME, Oh MC, Oh T, Sayegh ET, Kaur G, Sun MZ, Bloch O and Parsa AT: The role of epidermal growth factor-like module containing mucin-like hormone receptor 2 in human cancers. Oncol Rev 8: 242, 2014.

65. Fernández-Vega I, García-Suárez O, García B, Crespo A, Astudillo A and Quirós LM: Heparan sulfate proteoglycans undergo differential expression alterations in right sided colorectal cancer, depending on their metastatic character. BMC Cancer 15: 742, 2015.

66. Pelizzaro-Rocha KJ, de Jesus MB, Ruela-de-Sousa RR, Nakamura CV, Reis FS, de Fátima A and Ferreira-Halder CV: Calix[6]arene bypasses human pancreatic cancer aggressiveness: Downregulation of receptor tyrosine kinases and induction of cell death by reticulum stress and autophagy. Biochim Biophys Acta 1833: 2856-2865, 2013. 
67. Saovapakhiran A, D'Emanuele A, Attwood D and Penny J: Surface modification of PAMAM dendrimers modulates the mechanism of cellular internalization. Bioconjug Chem 20: 693-701, 2009.

68. Wright EM, Loo DD and Hirayama BA: Biology of human sodium glucose transporters. Physiol Rev 91: 733-794, 2011.

69. GuoGF, Cai YC,Zhang B, XuRH,Qiu HJ,XiaLP,Jiang WQ,HuPL, Chen XX, Zhou FF, et al: Overexpression of SGLT1 and EGFR in colorectal cancer showing a correlation with the prognosis. Med Oncol 28 (Suppl 1): S197-S203, 2011.

70. Parimi S, Barnes TJ, Callen DF and Prestidge CA: Mechanistic insight into cell growth, internalization and cytotoxicity of PAMAM dendrimers. Biomacromolecules 11: 382-389, 2010.

71. Crocker PR, McMillan SJ and Richards HE: CD33-related siglecs as potential modulators of inflammatory responses. Ann N Y Acad Sci 1253: 102-111, 2012.

72. Virgo P, Denning-Kendall PA, Erickson-Miller CL, Singha S, Evely R, Hows JM and Freeman SD: Identification of the CD33-related Siglec receptor, Siglec-5 (CD170), as a useful marker in both normal myelopoiesis and acute myeloid leukaemias. Br J Haematol 123: 420-430, 2003.

73. Hudson SA, Herrmann H, Du J, Cox P, Haddad el-B, Butler B, Crocker PR, Ackerman SJ, Valent $\mathrm{P}$ and Bochner BS: Developmental, malignancy-related and cross-species analysis of eosinophil, mast cell and basophil siglec-8 expression. J Clin Immunol 31: 1045-1053, 2011.

74. Potapenko IO, Haakensen VD, Lüders T, Helland A, Bukholm I, Sørlie T, Kristensen VN, Lingjaerde OC and Børresen-Dale AL: Glycan gene expression signatures in normal and malignant breast tissue; possible role in diagnosis and progression. Mol Oncol 4: 98-118, 2010.
75. Guo H, Nagy T and Pierce M: Post-translational glycoprotein modifications regulate colon cancer stem cells and colon adenoma progression in $\mathrm{Apc}^{\mathrm{min} /+}$ mice through altered WNT receptor signaling. J Biol Chem 289: 31534-31549, 2014.

76. Radisky DC, Levy DD, Littlepage LE, Liu H, Nelson CM, Fata JE, Leake D, Godden EL, Albertson DG, Nieto MA, et al: Raclb and reactive oxygen species mediate MMP-3-induced EMT and genomic instability. Nature 436: 123-127, 2005.

77. Ferrari G, Cook BD, Terushkin V, Pintucci G and Mignatti P Transforming growth factor-beta 1 (TGF-beta1) induces angiogenesis through vascular endothelial growth factor (VEGF)-mediated apoptosis. J Cell Physiol 219: 449-458, 2009.

78. Dings RP, Miller MC, Nesmelova I, Astorgues-Xerri L, Kumar N, Serova M, Chen X, Raymond E, Hoye TR and Mayo KH: Antitumor agent calixarene 0118 targets human galectin-1 as an allosteric inhibitor of carbohydrate binding. J Med Chem 55: 5121-5129, 2012.

79. Liu WC, Lin YL, Spearman M, Cheng PY, Butler M and Wu SC: Influenza virus hemagglutinin glycoproteins with different $\mathrm{N}$-glycan patterns activate dendritic cells in vitro. J Virol 90: 6085-6096, 2016

80. Abiola M, Favier M, Christodoulou-Vafeiadou E, Pichard AL, Martelly I and Guillet-Deniau I: Activation of Wnt/beta-catenin signaling increases insulin sensitivity through a reciprocal regulation of Wnt10b and SREBP-1c in skeletal muscle cells. PLoS One 4: e8509, 2009. 